\title{
Análisis semiótico y de discurso del programa infantil PJ Mask o Héroes en pijamas
}

\author{
Semiotic and discourse analysis of the children's program \\ PJ Mask or Héroes en pijamas
}

\author{
Briggette Dayanna Vega-Barriga \\ Universidad Nacional de Loja, Ecuador \\ briggette.vega@unl.edu.ec \\ https://orcid.org/0000-0001-7294-3989
}

Mónica Maldonado-Espinosa

Universidad Nacional de Loja, Ecuador monica.maldonado@unl.edu.ec

https://orcid.org/0000-0002-7521-6303

Recibido: 21/03/2021 Revisado: 28/04/2021 Aceptado: 18/05/2021 Publicado: 01/09/2021

\begin{abstract}
Resumen
Este trabajo investigativo analiza el discurso de la serie infantil PJ Masks o Héroes en pijamas. El objetivo de nuestro estudio es determinar los recursos visuales y lingüísticos utilizados en la construcción del mensaje. Este análisis nos permitirá reconocer las características discursivas recurrentes, respecto al lenguaje utilizado y los elementos de la semiótica visual, que permiten una respuesta positiva del público infantil. Se propuso una metodología cualitativa a través de fichas de observación y análisis de discurso y se identificaron las características lingüísticas y gráficas presentes en las dos temporadas de la serie infantil. En la serie reconocemos un lenguaje sencillo, palabras y frases que se repiten en todos los episodios. El mensaje gira en relación con un problema que debe enfrentar uno de los héroes, los conflictos que este le crean y cómo con el apoyo de sus amigos lo supera. La parte semiótica visual refuerza el discurso, permite que las niñas y los niños identifiquen los colores del vestuario y los lugares especiales. Las estrategias discursivas empleadas en la serie PJ Mask responden a una serie de mensajes que buscan reforzar valores en las niñas y los niños, a través de la fórmula de repetición continua de un mensaje cambiando lo negativo a positivo. Con respecto a lo semiótico se trabajan colores saturados e intensos, locaciones únicas y símbolos que identifican a cada personaje, cada héroe tiene un color y un símbolo.
\end{abstract}

\section{Palabras clave}

Dibujos animados, programa infantil, discurso, series, personajes, mensaje, audiovisual.

Forma sugerida de citar: Vega-Barriga, B.D., \& Maldonado-Espinosa, M. (2021). Análisis semiótico y de discurso del programa infantil PJ Mask o Héroes en pijamas. Universitas-XXI, 35, pp. 83-102. https://doi.org/10.17163/uni.n35.2021.04 


\begin{abstract}
This investigative work analyzes the discourse of the children's series PJ Masks. The objective of our study is to determine the visual and linguistic resources used in the construction of the message. This analysis will allow us to recognize the recurring discursive characteristics, regarding the language used and the elements of visual semiotics, which allow a positive response from the children's audience. A qualitative methodology was proposed through observation cards and discourse analysis, the linguistic and graphic characteristics present in two seasons of the children's series were identified. In the series we recognize a simple language, words and phrases that are repeated in all episodes. The message revolves around a problem that one of the heroes must face, the conflicts that this creates for him and how with the support of his friends he overcomes it. The visual semiotic part reinforces the speech, allows the children to identify the colors of the costumes and the special places. The discursive strategies used in the PJ Mask series respond to a series of messages that seek to reinforce values in children, through the formula of continuous repetition of a message, changing the negative to the positive. With regard to the semiothic, saturated and intense colors, unique locations and symbols that identify each character are worked, each hero has a color and a symbol.
\end{abstract}

\title{
Keywords
}

Cartoons, children's program, speech, series, characters, message, audiovisual.

\section{Introducción}

Existen varios estudios sobre la influencia del cine y la televisión sobre las audiencias (Lozano, 2008; Álvarez, 2020). La teoría de la aguja hipodérmica, la teoría del framing, el análisis del contenido y el de los mensajes ha cobrado importancia en la forma en que estos llegan e inciden en los públicos (Paiz-Malespín, 2016; Díaz-Bohórquez \& Moreno-Acero, 2021). Incidencia que ayuda a la publicidad y al crecimiento de los públicos (ÁlvarezSan Román, 2012).

El contenido siempre está en estudio y cada vez se abordan nuevos temas como la competencia mediática (Caldeiro-Pedreira et al., 2017), el género (Arredondo-Trapero et al., 2016), el machismo (Quintas-Froufe \& Vázquez-Gestal, 2020), la violencia (Ortega-Vázquez, 2020), el racismo (Maeda-González, 2020), la discriminación o el rol de la mujer (Rosero- Or- 
tega \& Guerrero-Barros, 2019). Consideramos que los códigos semióticos, los códigos visuales y las estrategias discursivas empleadas en los programas infantiles están ligadas al mensaje que quieren transmitir a los niños y las niñas (De los Reyes-Lozano, 2015; Sánchez, 2015). Estos mensajes pueden estar ligados a los procesos de aprendizaje y las experiencias infantiles en cada una de sus etapas de madurez y crecimiento (Ramírez-Blázquez \& Sánchez-Cárdenas, 2019).

La serie Héroes en pijamas está dirigida a un público infantil de entre tres a cinco años de edad. Hasta la fecha se han observado dos temporadas, con capítulos de 23 minutos de duración y con una muestra de nueve episodios de la primera y segunda temporada, los mismos que contienen dos episodios. La muestra se determina como 18 episodios por temporadas. Considerando que el discurso y la semiótica visual utilizada en cada episodio gira en torno a un valor o la superación de los miedos y conflictos de los protagonistas (Fielbaum-Schnitzler \& Portales-González, 2010; Uscanga-Castillo, 2020).

Nos plantemos como objetivo general realizar un análisis semiótico y discursivo de la serie infantil Pj Masks o Héroes en pijamas, para determinar qué recursos visuales utilizan en la construcción de la imagen de la serie y cómo a través del discurso llegan al público infantil (Hidalgo-Rodríguez \& Pertíñez-López, 2005).

A partir de este objetivo surgen tres objetivos secundarios que nos permitirán reforzar el análisis: analizar la serie de animación infantil Pj Masks o Héroes en pijamas y determinar los recursos visuales y cómo los utilizan en la construcción de la imagen. Determinar a través del análisis discursivo el mensaje de la serie infantil Pj Masks o Héroes en pijamas y cuáles son los elementos linguiísticos que se utilizan en la construcción del mensaje.

La animación infantil apareció mediante caricaturas filmadas (JiménezSánchez et al., 2019; Castro \& Sánchez, 1999). La primera obra se tituló Humorous phases of funny faces, nació de manos de James Stuart Blackton en 1906, no tenía un argumento establecido y duraba tres minutos. En ella se mostraban dibujos que cambiaban de expresión plasmados en una pizarra (Greenberg, 2018; Marín, 2009). En 1913, John R. Bray y Raoul Barré desarrollaron la técnica de dibujos animados sobre acetatos, de esta forma se evitaba la tarea de dibujar todo el fotograma, se podía separar el fondo de los personajes e incluía el uso de color de forma manual (Smith, 1977).

En referencia al fotograma, Valdivieso (2014) destaca el trabajo de Walter Lanz creador de Buggs Bunny, Goul y Harrison que fueron los creado- 
res de Krazy Kat, Otto Messmer y Pat Sulivan creadores de El gato Félix o Max Fleischer creador de Betty Boop. Menciona la entereza de Walt Disney por crear "su propia productora de animación y fragmentando el trabajo en diferentes fases de las que se encargaban distintos grupos de trabajo" (Valdivieso, 2014, p. 93). Disney no solo convirtió la animación en una cadena de producción, sino que inventó la máquina de toma de planos múltiples o cámara multiplano, con lo que generó la ilusión de profundidad (VaquerizoDomínguez, 2020; Porto-Pedrosa, 2014).

Con la llegada de nuevas tecnologías, John Whitney creó Motion Graphics Inc. en 1960 produciendo efectos de luz generados por ordenador (Betancourt, 2020). En 1982 apareció la primera película con animación digital de carácter comercial, su nombre fue Tron. Fue producida por Disney y dirigida por Steven Lisberger (Gómez de la Muñoza, 2020). En 1993 se logró apreciar una serie de televisión creada con ordenador. Reboot fue producida en Canadá por la compañía Mainframe Entertainment y creada por Ian Pearson, Gavin Blair, Phil Mitchell y Jhon Grace (Sawicki \& Moody, 2020). La investigación en técnicas de la animación que simulen la realidad, llegó con Pixar y la película Toy Story en 1995, revolucionando la animación 3D (AlJbouri \& Pomerantz, 2020).

\section{Pj Masks: Héroes en pijamas}

Esta serie infantil de televisión cuenta las aventuras de dos niños y una niña: Greg, Connor y Amaia, que durante la noche se convierten en Gecko, Catboy y Ululette para salvar el día (Godsave, 2018). Basada en los libros 'Les Pyjamasques' del autor francés Romuald Racioppo (Sardo, 2018). Producida por Frog Box, France Télévisions, Walt Disney Television y Entertainment One, bajo la dirección de Christian De Vita, Merle Ann Ridley, Wilson Dos Santos. En 2018 fue nominada en los Premios Annie a Mejor producción animada preescolar para TV (Grimmer, 2019).

\section{Metodología}

Para nuestra investigación, se analizaron las temporadas 1 y 2, tomando una muestra equilibrada de cada temporada. PJ Marks (2015) su primera temporada fue lanzada en septiembre de 2016 en Latinoamérica y finalizó el 
14 de abril de 2017. Para analizar cada temporada se escogió tres episodios desde el inicio, tres de la mitad y tres del final.

En la cuestión de imagen se analizaron los códigos semióticos, de arte y literatura; simbólicos; y, de morfología del relato. Los códigos lógicos como paralingüísticos, gestos de señales y programas; epistemológicos; y, de artes adivinatorias. Los códigos sociales como identidad, de cortesía, de naturaleza, de protocolo, de ritos, de moda, y de juego (Cargnin, 2019).

Sobre el discurso se emplearon tres estrategias: las estrategias discursivas; las estrategias de persuasión y de manipulación de la teoría del análisis crítico del discurso propuestas por van Dijk (2003); y, las macroestrategias semánticas de la teoría lingüística cognitiva (Delicia, 2011).

Las fases investigativas fueron tres. La primera fase exploratoria-descriptiva, que corresponde a la observación de elementos visuales y de texto. Se recogieron datos como movimientos de cámara, escenografía, vestuario, íconos, símbolos y colores de las escenas más representativas de la serie, en sus dos temporadas. Se expusieron las características de los protagonistas, con su respectivo álter ego. Con respecto al discurso, tomando datos como frases repetitivas, palabras propias de los personajes principales, léxico, y las temáticas y mensaje de los capítulos (Ortega-Mohedano et al., 2018). La segunda fase de la investigación de carácter analítico, corresponde a la correlación de datos y su análisis en función de los códigos semióticos, los códigos visuales y las estrategias discursivas.

La tercera fase fue la sintética. En ella se relacionaron e integraron todos los factores derivados del análisis semiótico y de discurso. De modo que den respuesta a los objetivos planteados en la investigación, respecto a los propósitos del estudio semiótico y el análisis discursivo.

Para la observación se tomó en cuenta a los personajes, escenografía, movimientos de cámara, planos, colorimetría, vestuario, atrezo, íconos, símbolos, síntesis del episodio, léxico, palabras y frases repetitivas, mensaje de cada episodio y nombre de los superpoderes. Se tabularon dos aspectos generales: el semiótico, donde se ubicaron, de acuerdo con cada episodio, la escenografía, personajes, vestuario, atrezo, colores, símbolos, íconos, planos y movimientos de cámara. Y el aspecto discursivo, síntesis, mensaje, frases frecuentes, léxico y frases de superpoderes. Con estos resultados se contabilizaron los datos en dos fases: sobre las palabras repetitivas, y sobre la relación entre mensaje del episodio y sus palabras o frases repetitivas. Se integraron los análisis para identificar a los personajes sobre las variables 
observadas y para responder a la construcción del mensaje, tal como se propuso en los objetivos de investigación.

\section{Resultados}

\section{Análisis semiótico por escenas}

Se ha dividido cada episodio en cuatro escenas: inicio, mórfosis, combate y solución. La escena de inicio es donde empieza la historia. Aquí se conocen a los personajes y el problema que se debe resolver. En la escena de mórfosis se ve la transformación de los personajes principales a superhéroes. En la escena de combate se vive la lucha de los superhéroes con los villanos hasta lograr la solución a los problemas. Y en la escena de solución los personajes principales dejan su papel de superhéroes para disfrutar la solución del conflicto junto a su entorno.

La mórfosis de los personajes aparece en las escenas de inicio en 35 episodios de los 36 que conforman la muestra de la primera y segunda temporada de estudio. En la escena de combate aparecen los 36 episodios y la escena de solución aparece en 22 episodios de los 36 tomados como muestra. Se decidió hacer una interpretación de acuerdo con estas cuatro escenas principales y la información recogida en siete variables: la escenografía, los personajes, el vestuario, el atrezo, los colores, los símbolos y los íconos.

\section{Análisis general del bloque de escenas de inicio}

El discurso visual del bloque de inicio se apoya en la utilización de dos escenografías, tcomo la escuela y el museo, refiriéndose a los escenarios en los que se presenta a los personajes y al problema. Los personajes principales son Connor, Greg y Amaya, quienes son compañeros de la misma clase y también son vecinos. Se muestra la relación de amistad y compañerismo.

Respecto al vestuario, los personajes principales y secundarios utilizan zapatos deportivos durante todo el bloque de inicio, lo que indica la comodidad para la edad preescolar en la que ellos se encuentran. En cuanto al atrezo, se observan pulseras con el antifaz del alter ego que representa cada personaje, las mismas que se muestran al finalizar el bloque de inicio como 
símbolo de unidad y trabajo en equipo. En lo que se refiere a colores, el blanco y el verde son los más utilizados en este bloque debido a que en todos los episodios, excepto uno, los escenarios aparecen en modo diurno y bastante iluminados, el color verde se muestra en la gran cantidad de árboles que existen tanto dentro de la ciudad como en el parque y en el bosque. Uno de los personajes principales utiliza el color verde en su ropa.

Los símbolos más utilizados la calcomanía de lagarto que se encuentra en la ropa y otras pertenencias de Gecko es la más utilizada, al igual que las rayas o rayos que aparecen en las pertenencias de Connor, lo que indica los poderes de reptil y el poder de velocidad, respectivamente. Sobre los iconos, los predominantes y establecidos dentro de la serie como identificadores de los superhéroes, son los antifaces de cada uno de los personajes principales.

Los planos que más se emplearon fueron los planos de conjunto, ya que en la escena de inicio se contextualiza el entorno de los superhéroes, mostrándolos en conjunto junto a compañeros de clase, profesores o vecinos. Sobre los ángulos de cámara, los más utilizados fueron los ángulos visuales picados, debido a que los personajes principales son enfocados desde lo alto, ya sea para observar lo que llevan en sus manos, así como para identificar los elementos del entorno. El movimiento de cámara empleado de manera recurrente en este bloque, fue el movimiento óptico de zoom out, lo cual responde al hecho que los personajes suelen observar con atención o concentrarse en algo, por lo que se utiliza este movimiento óptico para oxigenar, mostrando un plano más amplio.

\section{Escenas de mórfosis}

El discurso visual del bloque de mórfosis, en los 35 episodios de los 36 en total, se enfoca en la misma escenografía, personajes, vestuario, atrezo, color, símbolos e íconos. Estos elementos responden a la escenografía de habitaciones y ciudad, ya que cada personaje aparece en su respectiva habitación, con su pijama y luego presiona en su pulsera para la mórfosis.

Los colores que más se utilizan son el azul y verde, predominan en la ciudad y en las habitaciones donde guardan los trajes dos de los personajes principales. Los símbolos más utilizados son los búhos en la habitación de Ululette, ya que tiene este tipo de animales tallados en madera. En cuanto a los íconos, los más utilizados son los antifaces, ya que aparecen en el vestuario y atrezo de los personajes, así como en algunas escenografías. 
El plano más utilizado es el plano entero, porque muestra la pose de los superhéroes antes y después de que suceda la transformación. El ángulo lateral predomina debido a que enfoca de manera disimulada a los personajes, quienes realizan actividades comunes de antes de dormir. Respecto a los movimientos de cámara, aparecen como más utilizados tres movimientos físicos u ópticos de la cámara: paneo, tilt up y tilt down, estos responden a que los personajes principales deben elevarse antes de la transformación y descender luego de la misma, y con el paneo se permite conocer el entorno en el que se desenvuelven.

\section{Escenas de combate}

El discurso visual del bloque de combate se enfoca en dos escenografías: la de ciudad y el cuartel de los PJ Masks. En este bloque los personajes principales son Catboy, Gekko y Ululette. Sin embargo, el villano que más aparece es Luna. En cuanto al vestuario los personajes utilizan su pijama de cuerpo entero y el pasamontaña que son su traje de superhéroes. Sobre el atrezo el más utilizado es la cola, ya que la utiliza Catboy, Gecko y Armadiland. El color más utilizado es el negro, ya que todos los escenarios y todas las situaciones se dan durante la noche, donde muchos objetos no se ven o aparecen entre las sombras. Sobre los símbolos, los más utilizados son las plumas y escamas ya que las plumas aparecen en el traje de Ululette y sus diferentes pertenencias. Mientras que las escamas aparecen en el traje de Gecko y sus pertenencias, así como en el traje de Armadiland que es otro personaje secundario. El ícono que más se utiliza son los antifaces de cada uno de los superhéroes principales.

Entre los planos registrados el plano entero predomina, ya que permite observar e identificar a los personajes, tanto en su vestuario y atrezo como en sus movimientos corporales, también se emplea en las poses de lucha o para mostrar nerviosismo.

Los ángulos de cámara utilizados, fueron los ángulos visuales picados, debido a que los superhéroes y los villanos escalan, trepan o vuelan en algún momento, de modo que ven desde lo alto a sus adversarios o a las situaciones de peligro.

Uno de los movimientos físicos u ópticos más utilizado es el zoom in, lo que responde a la necesidad de enfocar algo en específico, ya sea porque lla- 
ma la atención, porque es un elemento de lucha, un objeto que se quiere recuperar o una reacción facial del personaje. Esto nos permite sentirnos parte de las acciones que involucran a los personajes de manera personal.

\section{Escenas de solución}

El discurso visual del bloque de solución se enfoca en varias coincidencias del bloque de inicio. Respecto a la escenografía la más utilizada es la de estadio en la que se suele disfrutar de haber solucionado los problemas. Los personajes qué más aparecen son Connor, Greg y Amaya, los mismos que utilizan zapatos deportivos, al igual que otros personajes secundarios demostrando la comodidad de la etapa escolar.

Respecto al atrezo, aparecen más las lentes redondas de Ululette, las pulseras de antifaz y los peinados de los tres personajes principales. En lo que se refiere al color, el rojo y el azul marino son los más utilizados debido a los diferentes componentes de las escenografías y los trajes de dos de los personajes principales. Sobre los símbolos, la calcomanía de lagarto y las rayas o rayos son los más empleados ya que aparecen en las diferentes pertenencias, accesorios, vestuario y escenografía de los personajes principales, en este caso Greg y Connor. En cuanto a los íconos, los más empleados son los antifaces de cada uno de los personajes principales, que también aparecen dentro del vestuario y atrezo.

El plano más destacado es el de conjunto, la razón responde a que, en la solución, los personajes comparten actividades con sus amigos, compañeros o vecinos, como una manera de disfrutar el resultado de "salvar el día", como ellos dicen. Del mismo modo, el ángulo visual predominante es el lateral, porque es común observar cómo los personajes se desenvuelven como amigos y disfrutan de aquello que los villanos querían quitarles, por ello, a modo de disimulo, la cámara nos permite observarlos en un ángulo lateral.

El movimiento físico u óptico empleado con predominancia es el zoom out, puesto que este bloque es de cierre, por lo tanto, busca oxigenar el encuadre y contextualizar. Al finalizar el episodio utiliza este movimiento óptico como una manera de despedirse. 


\section{Análisis del discurso}

De acuerdo con lo observado, las palabras que más se repiten son: héroes en pijamas, Luna, poder, robar, Ninja, roca y jugar. Las temporadas observadas, en el ámbito del discurso tiene el protagonismo de los héroes en pijamas o PJ Mask. Este nombre se repite 38 veces, que corresponden al 6 $\%$, tomando en cuenta que es la frase propia antes del combate y al momento de lograr la solución.

Estas series cuentan con más episodios de la villana Luna Girl y el Ninja Nocturno. Se justifica que "Luna" y "Ninja" estén entre las palabras más repetidas, con $5 \%$ y $3 \%$ respectivamente. Luna tiene dos aparatos tecnológicos con esta palabra tabla lunar e imán lunar. Ninja tiene a sus secuaces denominados Ninjalinos. Es por ello que tienen mayor probabilidad que se repita su nombre durante las dos temporadas.

"Jugar", "robar" y "poder" tienen un $3 \%, 3 \%$ y 5\%, respectivamente. Estas se repiten debido a que, al inicio o fin de cada episodio, héroes se encuentran jugando en la escuela, el estadio, las casas o en el cuartel de los $P J$ Mask. Todos los villanos roban algo, lo que hace que esta palabra se repita constantemente entre los villanos y los héroes. Todos los villanos quieren tener el poder: Luna quiere apoderarse del satélite de la Tierra y dominar a los humanos, Romeo quiere el poder a través de sus inventos, y los Ninjas Nocturnos quieren tener todo lo que tienen los niños y las niñas de la ciudad, todo esto se refleja en la repetición de esta palabra al momento de hacer sus fechorías. "Roca" tiene el 3\% de repeticiones, debido a que existen dos episodios dedicados a Gecko y su roca especial y sobre montañas.

\section{Relación entre mensaje del episodio y sus palabras $o$ frases repetitivas}

Entre los temas repetidos están trabajo en equipo, autoestima, paciencia, dar oportunidades y constancia. Esta serie demuestra que el principal valor es el trabajo en equipo, representado con el $20 \%$ de repeticiones en el mensaje de sus episodios. Este valor se demuestra en todos los episodios. También resaltan otros mensajes como autoestima con el $14 \%$, paciencia con el $11 \%$, dar oportunidades y constancia con el $6 \%$ del total. Los temas que no se repiten, pero que se abordan en el $44 \%$ restante, son: valentía, perdón, 
precaución, saber cuidarse, humildad, consideración, responsabilidad, ser ordenado, solidaridad, liderazgo, saber escuchar, tolerancia, explorar, innovar, ser correctos y confianza.

Estos valores identifican a los personajes porque son un equipo con superpoderes, habilidades distintas y personalidad distintos que deben unir sus esfuerzos para lograr los objetivos y mantener su amistad (Rajadell et al., 2005).

\section{Discusión}

La serie infantil aplicó la estrategia de Construcción Textual, de la teoría de la Lingüística Textual. Esta estrategia indica que el lenguaje permite intercambiar significados y expresarlos en la construcción textual. Los significados intercambiados responden a una relación triádica: nombre-poder-vehículo.

El personaje de Catboy o Gatuno, que hace alusión a "niño gato" intercambia significado con las habilidades de los gatos y sus raíces felinas, como: oído sensible a altas frecuencias (oído felino), garras largas (rayas de gato), gran agilidad (super velocidad), vigorosa musculatura (super salto felino). Este personaje es masculino, sus colores predominantes son azul y negro, y representa a las habilidades de los felinos, especialmente los gatos. Su nombre de superhéroe es "Cat" = gato y "boy" = niño; y, su verdadero nombre es Connor, que lleva una "C" de cat=gato. La ropa de Connor y su traje de Catboy tienen predominancia de color azul y negro.

Tiene un automóvil denominado Gatomóvil y una moto en pijama para su personaje nocturno, mientras que tiene una patineta y una bicicleta para su personaje de niño. En su ropa y vehículos se encuentran los rayos que identifican la velocidad. Su traje de superhéroe tiene símbolos como antifaz con orejas y cola de gato. Entre sus frases, dentro de los combates, están "gatástrofe" cuyo significado es el mismo que catástrofe y "por mis bigotes" refiriéndose a algo que no pudo detectar a tiempo.

El personaje de Gecko, que hace alusión al nombre de un tipo de lagarto, intercambia su significado con las habilidades de este animal y sus raíces de reptil, como: excelente capacidad para adherirse (super agarre), fuerza de brazos y piernas (super fuerza), capacidad para tomar colores del ambiente (super camuflaje), las escamas y coraza (super escudo), y su destreza en el agua (super carrera sobre el agua). 
Este personaje es el menor, su color predominante es el verde, y representa a las habilidades de los reptiles, especialmente de los gekkos (un tipo de lagarto). Su nombre de superhéroe es Gecko, pero su verdadero nombre es Greg, que suena similar a Gecko. La ropa de Greg y su traje nocturno tienen predominancia del color verde, en la noche presenta una cresta y una cola de lagarto. En su ropa y vehículos encontramos símbolos de antifaz de Gekko, escamas y antideslizantes. Tiene un vehículo denominado Gekkomóvil y una moto en pijama para su personaje nocturno, mientras que tiene una patineta y una bicicleta para su personaje de niño. El Gekkomóvil tiene tracción de oruga, puede ir bajo el agua porque tiene cola para nadar y puede escalar paredes.

Entre sus frases representativas están: "reptiles roñosos" que significa que algo causa muchos problemas, "camaleones cósmicos" que referencia algo increíble, "serpientes sigilosas" o cuando quiere expresar cautela, "gekkos galopantes" cuando algo genera asombro y "serpientes saltarinas" cuando un episodio requiere saltar mucho.

El personaje de Ululette o Buhita, que hace alusión a esta ave y su especie, intercambia significados con habilidades como vista desarrollada (vista de búho), gran velocidad de vuelo (alas de búho torbellino y plumas de búho). Este personaje es femenino, sus colores predominantes son rojo y rosado, y representa a las habilidades de las aves, especialmente los búhos.

Su nombre de superhéroe, en español es Buhíta, sin embargo, en español latino no se reconoce algún significado. Su verdadero nombre es Amaya, que lleva una "A", posiblemente de ave, pero ninguna relación más con los búhos. La ropa de Amaya y su traje nocturno tienen predominancia de los colores rojo y rosado. En su ropa y vehículos encontramos símbolos de antifaz y plumas de búho que la identifican. En su traje existe una capa y un antifaz de plumas. Este personaje tiene un vehículo denominado búhodeslizador, con alas y patas de ave para aterrizar, y una moto en pijama para su personaje nocturno, mientras que tiene una patineta y una bicicleta para su personaje de niño. Entre sus frases destacadas está "por todas mis plumas", para referirse a algo raro o exagerado que sucede y que es difícil de resolver.

Esta estrategia relaciona significados que permiten dar sentido de pertenencia en la audiencia, en este caso, público infantil en edad preescolar. Lo que tenemos son colores básicos como azul, rojo, verde y negro, de manera predominante, los cuales son más saturados en trajes que los identifican como héroes y con tonalidades suaves cuando no son héroes. Es así que, la 
escenografía, los colores, el atrezo y el vestuario dan identidad a los personajes principales, lo que busca generar pertenencia en el espectador.

Respecto a los códigos semióticos, uno de estos son los estéticos, los cuales se emplearon en arte y literatura, ya que se muestra elementos de la cultura china y simbolismos propios de la festividad de Halloween; simbólicos como los elementos de la cultura china; y, de morfología del relato como las analogías gato y Catboy, señalando su miedo, búho y Ululette, señalando su inteligencia, y la de lagarto y Gecko, indicando los parches antideslizantes para trepar.

Con lo referente a los códigos lógicos, se utilizaron los paralingüísticos, ya que muestran acciones que expresan emociones (kinésico), gestos que sugieren autoridad o respeto entre compañeros y docentes (proxémico), y la gestualidad y entonación al hablarse entre personajes (prosódico); de señales y programas, como flechas y los letreros en las diferentes escenografías; epistemológicos, como la idea central de la lucha entre el bien y el mal, a través de sus poderes $\mathrm{u}$ aparatos tecnológicos; $\mathrm{y}$, de artes adivinatorias, como la leyenda del anillo de la Ninjahabilidad, los símbolos de la montaña misteriosa y de la fiesta de Halloween.

Sobre los códigos sociales, se emplearon los signos de identidad, la pijama y antifaz en los Héroes en pijamas, insignias de ninja, la tabla lunar en forma de luna, los colores representativos de superhéroes y villanos, los carteles en el museo, escuela, zoológico y otros sitios; de cortesía, al gestualizar y cambiar el tono de voz para dirigirse entre amigos o entre adversarios y al emplear signos como los dos dedos de "amor y paz" para indicar amistad o tregua; y, de naturaleza, como el desorden en la habitación de Greg, indicando que debe cumplir sus responsabilidades.

Como parte de los códigos sociales, se utilizaron los códigos de protocolo, identificando el saludo cuando es hacia un compañero de clase o hacia un enemigo o el utilizar una tarjeta de invitación; de ritos, cuando los ninjalinos realizan poses en conjunto antes de atacar; de moda, cuando uno de los niños utiliza el traje de Capitán América para sentirse poderoso frente a sus amigas y amigos y los héroes nocturnos; de juego, como las mascotas y peluches de los protagonistas que muestran una realidad social.

Los códigos visuales reforzaron a los códigos semióticos señalados anteriormente. Los códigos perceptivos fortalecieron las analogías de la morfología del relato, ya que se emplean los colores, vestuario, atrezo y vehículos característicos de los superhéroes. Los códigos de reconocimiento, 
aplicados en los antifaces de los superhéroes, ya que estos se pueden ver en los escenarios, vestuarios y vehículos, creando identidad. Los códigos de transmisión, que determinan al espectro radioeléctrico de telecomunicaciones como canal de difusión de esta serie televisiva. Los códigos tonales que refuerzan a los códigos paralingüísticos. Los códigos icónicos como los símbolos en la pantalla táctil y en el robot en pijama. Los códigos iconográficos, en los que hablamos de los antifaces como representación de un personaje. Los códigos retóricos, como los dedos de "amor y paz".

Respecto a la primera fase, la serie infantil PJ Masks-Héroes en pijamas aplicó las estrategias discursivas de Análisis de Discurso propuestas por Prieto (1999). Tenemos sobre el sentido de oportunidad, por ejemplo, en el episodio de la Crisis nebulosa de Catboy, en que la villana, Luna, señala a Catboy como "gatito miedoso", porque él tiene miedo a mojarse. Esta situación también le sucede a Romeo, el villano en el episodio de El problema de Ululette con el pterodáctilo, donde este denomina como "gatito asustadizo" al mismo protagonista. Esto indica la utilización de metáforas.

En esta primera fase vemos cómo se crea en los niños y niñas relaciones analógicas entre las destrezas, aptitudes o características de un animal con respecto a una persona. Los mensajes utilizan palabras repetitivas para direccionar su mensaje sobre una palabra clave que señale lo que queremos o no ser o hacer, por ello, asustadizo o miedoso se repite para indicar cómo actúa alguien cuando siente temor y para proponer una solución, en este caso, ser valiente.

En lo que se refiere a la segunda fase, la serie infantil PJ Masks-Héroes en pijamas aplicó la estrategia Memoria a largo plazo (MLP) de la teoría del Análisis crítico del discurso: estrategias de persuasión y de manipulación, propuesta por van Dijk (2006). El discurso está enfocado hacia tres aristas: el conocimiento, que permitirá que los personajes valoren el trabajo en equipo, que innoven en su planificación y que exploren nuevas posibilidades. Las actitudes como paciencia, constancia, valentía, perdón, autoestima, precaver, humildad, consideración, responsabilidad, solidaridad, orden, tolerancia, escuchar, autocuidado, confianza y ser correctos, que posibilitan el cambio personal y el desarrollo humano; y, las ideologías que, aunque no se observan mensajes ni palabras que hagan alusión a ideologías políticas, religiosas, sexuales o económicas. Esta serie busca promulgar una cultura de paz, donde los buenos protejan a los indefensos y detengan a los malos, incluso, que promuevan el cambio en sus actitudes para ser reinsertados en la sociedad. 
La serie aplicó las macroestrategias semánticas de la teoría lingüística cognitiva. Evidenciando la relación entre palabras y frases repetitivas dentro de los mensajes, encontramos los hiperónimos y sus hipónimos: "vehículo": tren y aviones, "animal": gato, pterodáctilo, antilosaurio, diplodocus y T-rex. Los tres tipos de sinonimia: la conceptual en palabras como ansioso, impaciente, apresurado, veloz, rápido; la referencial, en palabras como prisa, lo siento; la connotación, en caramelos y dulces, huesos y dinohuesos, montaña y romemontaña, misteriosa y mística; la polisemia en Gekko, observatorio, medallón, paso, copa, plasma, estrella, muñeco, ejército, trampa, pintura, creído y dulce; la homonimia, dentro de los homógrafos como Gekko, paso, copa, lunar, justo y observatorio; y, la antonimia de complementariedad en relaciones como amigo-enemigo, héroe-villano, lento-rápido, miedoso-valiente y bueno-malo.

En esta segunda fase vemos cómo se enriquece el léxico de los niños y niñas al utilizar la sinonimia, antonimia, hiperonimia y polisemia. Si bien, los niños y niñas desconocen sus conceptos, lo que sí pueden hacer es replicar conforme se desarrollen. Ahí radica la razón para que las series sean repetitivas. Las palabras antónimas se emplean para direccionar el mensaje sobre lo que se debe evitar o sobre cómo se debe o no actuar.

\section{Conclusiones}

En lo semiótico se identifican variables que son repetitivas, como la ropa, las locaciones, la escenografía, en algunos casos varían. Se repiten sitios como la escuela, el museo, el estadio y el cuartel y la ciudad, logrando que quien observa reconozca fácilmente los espacios, los ubique, los interiorice y los asocie a cada uno de los personajes. Los colores juegan un papel importante al momento de marcar la diferencia entre la vida cotidiana de los niños y las niñas y la de héroes o villanos. Para ello utilizan colores primarios y saturados en la noche, colores que se perciben con facilidad y permiten observar con nitidez las imágenes y los movimientos y acciones pues generan contraste. Lo que permite distinguir correctamente a cada uno de los personajes y sus características y símbolos. A diferencia de los colores utilizados durante el día, estos son luminosos, poco saturados, con ellos se provee de una atmósfera clara y se otorga el mayor impacto visual a la noche que es donde se suceden y se resuelven los conflictos. 
Respecto al discurso en general, se aplicaron las estrategias según el orden de las partes del discurso: estrategias de inicio, específicamente, el de la de puesta en escena. Esto permitió identificar que, al inicio de los episodios, se muestran conversaciones entre los protagonistas, incluyendo algunas veces a personajes extras como profesores, compañeros de clase u otros villanos. Mediante estos diálogos conocemos los gustos de los protagonistas, sus miedos y el problema que deberán resolver durante su misión nocturna. En una ocasión se evidencia una estrategia de inicio incógnita, donde podemos ver a los personajes principales culminando una misión nocturna, pero ya entrando a un conflicto, lo que exige poner atención al discurso para saber qué pasará. Se comprende que la serie busca generar relaciones analógicas entre las destrezas, aptitudes o características de un animal con respecto a una persona. En los episodios se repiten palabras para direccionar el mensaje sobre una palabra clave que señale lo que queremos o no ser o hacer.

En lo que se refiere a estrategias de cierre de discurso se encontró un cierre imprevisible en todos sus episodios. Es decir, durante el combate, existen momentos en que parece que llegan a resolverlo todo, pero no es así. Lo que genera interés y, aunque se sabe que los héroes ganarán, se desconoce cómo o bajo qué estrategias. A esto se suma que existen episodios donde no se muestra la escena final diurna en la que todos disfrutan de la solución, sino que, algunos episodios de la segunda temporada, finalizan con la escena de combate. Mediante estas estrategias identificamos que el léxico de los niños y las niñas se ve influenciado con la sinonimia, antonimia, hiperonimia y polisemia expresadas de manera repetitiva en la serie, como una manera de quedarse en el inconsciente del niño y niña para que sea replicada.

La serie aplica los códigos del inconsciente que son parte de los códigos visuales. Mediante las diferentes variables, presentadas tanto en los héroes como en los villanos, se expresan situaciones psicológicas, entre ellas nervios, impaciencia, temor o egoísmo. De la misma manera, se busca generar reacciones como el aprendizaje de valores, las destrezas de los animales (lagarto, gato y búho), las aptitudes de los ninjas, la importancia de la ciencia y los aparatos tecnológicos, las cualidades de la luna, entre otras enseñanzas. 


\section{Bibliografía}

Al-Jbouri,E., \& Pomerantz, S. (2020). ANew Kind of Monster, Cowboy, and Crusader?: Gender Hegemony and Flows of Masculinities in Pixar Animated Films. Boyhood Studies, 13(1), 43-63. https://doi.org/10.3167/bhs.2020.130104

Álvarez-San Román, M. (2012). La percepción e identificación de niñas y niños con los personajes de las series televisivas de animación. Universidad de Oviedo. https://bit.ly/3wmctSU

Álvarez, C.L. (2020). Audiencias infantiles en televisión abierta. Actualidad Jurídica Iberoamericana, (13), 78-101. https://bit.ly/31FxFVZ

Arredondo-Trapero, F.G., Villarreal-Rodríguez, M.L., \& Echanizb-Arrondo, A. (2016). La inclusión de la mujer y la igualdad de género en las series de dibujos animados. Atenea (Concepción), (514), 125-137. http://dx.doi. org/10.4067/S0718-04622016000200125

Betancourt, M. (2020). The history of motion graphics. Wildside Press LLC.

Caldeiro-Pedreira, M.C., Maraver-López, P., \& Marín-Gutiérrez, I. (2017). Competencia mediática en la etapa infantil en España. Magis, Revista Internacional de Investigación, 20(10), 35-48. https://doi.org/10.11144/Javeriana.m10-20.cmei

Cargnin, F.A. (2019). Framework conceitual para a produção do humor visual no design de animações para crianças. Universidade Federal de Santa Catarina, Centro de Comunicação e Expressão, Programa de Pós-Graduação em Design, Florianópolis. https://bit.ly/3cLwdYG

Castro, K., \& Sánchez, J. (1999). Dibujos animados y animación: Historia y compilación de técnicas de producción. CIESPAL.

De los Reyes-Lozano, J. (2015). La traducción del cine para niños. Un estudio sobre recepción (Doctoral dissertation). Universitat Jaume I. https://bit.ly/3mp87Gp

Delicia, D.D. (2011). Estrategias inferenciales en la comprensión del discurso expositivo: En torno de la adquisición y el desarrollo de las habilidades lingüístico-cognitivas. RAEL: revista electrónica de lingüística aplica$d a,(10), 69-87$. https://bit.ly/3djXCzG

Díaz-Bohórquez, J.C., \& Moreno-Acero, I.D. (2021). Los padres de familia ante el consumo de televisión de sus hijos. Revista Interamericana de Investigación, Educación y Pedagogía, 14(1),133-150.https://doi.org/10.15332/25005421.3340

Fielbaum-Schnitzler, A., \& Portales-González, C. (2010). Para un análisis crítico del discurso de los dibujos animados. Propuestas metodológicas. Questión, 1(25). https://bit.ly/3rDGQRq 
Godsave, P.A. (2018). The Roles of Servant Characters in Restoration Comedy, 1660-1685. Georgia State University. https://bit.ly/31Ce2hE

Gómez de la Muñoza, P. (2020). La digitalización de la media: La evolución del CGI hacia la renderización no fotorrealista en Spider-Man: Un nuevo universo. Universitat Politècnica de València. https://bit.ly/3me17vN

Greenberg, R. (2018). How Animation Won Over the Lightning Sketch: Re-Evaluating Humorous Phases of Funny Faces. Animation, 13(2), 162-174. DOI: https://doi.org/10.1177/1746847718783641

Grimmer, T. (2019). Calling All Superheroes: Supporting and Developing Superhero Play in the Early Years. Routledge.

Hidalgo-Rodríguez, M.C., \& Pertínez-López, J. (2005). La calidad en los dibujos animados en televisión. Comunicar (25). https://bit.ly/2Ps5szu

Jiménez-Sánchez, A., Lavín, J.M., \& Gómez-Isla, J. (2019). Érase una vez..., la animación infantil española. Revista Ibérica de Sistemas e Tecnologias de Informação, E20: 36-48. https://bit.ly/39DX8Ui

Lozano, J.C. (2008). Consumo y apropiación de cine y TV extranjeros por audiencias en América Latina. Comunicar, 15(30), 67-72. https://doi. org/10.3916/c30-2008-01-010

Maeda-González, C.M. (2020). ¿Princesas de carne y hueso?: análisis del proceso de identificación de niñas mexicanas con las princesas Disney. Bonilla Artigas Editores.

Marín, J. (2009). Cine de dibujos animados. El Cid Editor.

Ortega-Vázquez, G.S. (2020). Comunicación, diversidad y desarrollo social. Ixaya. Revista Universitaria de Desarrollo Social, 10(19), 175-180. https://bit. ly/3cKJNeU

Ortega-Mohedano, F., Jiménez-Sánchez, A., \& Lavín, J.M. (2018). Industrias culturales y composición de los personajes en las series de animación infantil emitidas en España. Revista Latina de Comunicación Social, (73), 74-88. https://doi.org/10.4185/RLCS-2018-1246

Paiz-Malespín, G. (2016). Tejiendo el consenso desde la combinación de las agendas: Agenda Melding. Ciencia e interculturalidad, 19(2), 104-121. https://doi.org/10.5377/rci.v19i2.3122

PJ Masks (2015). Primera temporada: Romuald Racioppo. Toronto: Entertainment One. Digital, son., color. Exhibido por Amazon Prime Video.

Porto-Pedrosa, L. (2014). Proceso de socialización y cine de animación de Disney y Pixar: estudio del tratamiento y la recepción de los conflictos emocionales en la audiencia de 5 a 11 años. Universidad Complutense de Madrid. https://bit.ly/31Hc5Ao 
Prieto, D. (1999). El juego del discurso: manual de análisis de estrategias discursivas. Lumen.

Quintas-Froufe, N., \& Vázquez-Gestal, M. (2020). El Defensor de la audiencia de RTVE como mediador en la resolución de reclamaciones sobre el canal infantil Clan (2010-2015). Quaderns del CAC, 23 (46), 25-34. https://bit. ly/3sOkWw0

Rajadell, N., Pujol, M., \& Violant, V. (2005). Los dibujos animados como recurso de transmisión de los valores educativos y culturales. Comunicar, 13(25). https://bit.ly/31IbjmF

Ramírez-Blázquez, I., \& Sánchez-Cárdenas, B. (2019). La traducción musical: modalidades, estrategias y propuesta didáctica. Sendebar, 30, 163-197. https://doi.org/10.30827/sendebar.v30i0.8552

Rosero-Ortega, R.C., \& Guerrero-Barros, M.P. (2019). Racialidad, identidad y estereotipos en el cine ecuatoriano: estudio de recepción de la película A tus espaldas en los barrios La Magdalena y Chillogallo del sur de la ciudad de Quito. El ojo que piensa. Revista de cine iberoamericano, (18), 67-85. https://doi.org/10.32870/elojoquepiensa.v0i18.308

Sánchez, L.I. (2015). Veo Veo ¿qué ven? Uso y abuso de los dibujos animados. Fundación Inquietarte.

Sardo, R. (2018). C'era una volta la tv per ragazzi... contenuti narrativi e modelli linguistici web/televisivi per i digitali nativi. Lingue e culture dei media, 2(1), 1-57. https://doi.org/10.13130/2532-1803/9936

Sawicki, M., \& Moody, J. (2020). Filming the Fantastic with Virtual Technology: Filmmaking on the Digital Backlot. Routledge.

Smith, C. (1977). The Early History of Animation: Saturday Morning TV Discovers 1915. Journal of the University Film Association, 29(3), 23-30. https:// bit.ly/3cJmpOw

Uscanga-Castillo, A. (2020). El tratamiento de un niño con autismo en situación de vida complicada. Aperturas psicoanalíticas: Revista de psicoanálisis, (63), 3. https://bit.ly/3sIjP11

Valdivieso, C. (2014). Análisis de los dibujos animados emitidos en televisión: personajes, estilos y mensajes. Universidad de Granada. https://bit. ly $/ 3$ sJnImo

Van Dijk, T. (2003). La multidisciplinariedad del análisis crítico del discurso: un alegato a favor de la diversidad. En Ruth Wodak y Michael Meyer, Métodos de análisis crítico del discurso (pp. 143-177). Gedisa, https://bit. ly/3fxg $2 z \mathrm{~V}$ 
Van Dijk, T. (2006). Discurso y manipulación: Discusión teórica y algunas aplicaciones. Revista signos, 39(60), 49-74. http://dx.doi.org/10.4067/S071809342006000100003

Vaquerizo-Domínguez, E. (2020). Medios de comunicación y flujos culturales internacionales: la vigencia actual del informe McBride. Revista de Comunicación de la SEECI, (51), 43-62. https://doi.org/10.15198/seeci.2020.51.43-62 